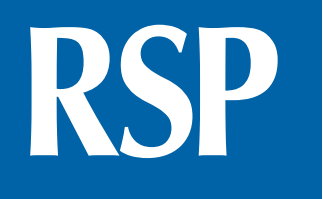

http://www.rsp.fsp.usp.br/
Revista de Saúde Pública

\title{
Factors associated with diagnosis of stages I and II lung cancer: a multivariate analysis
}

\author{
Isabel Cristina Martins Emmerick' iD, Anupama Singh" (iD, Maggie Powers' ${ }^{1}$ iD, Feiran Lou' iD, \\ Poliana Lin' (iD, Mark Maxfield' (ID, Karl Uy' iD \\ I University of Massachusetts Medical School. Division of Thoracic Surgery. Department of Surgery. Worcester, \\ Massachusetts, USA \\ " University of Massachusetts Medical School. Worcester, Massachusetts, USA
}

Correspondence:

Isabel Cristina Martins Emmerick

UMass Memorial Healthcare/

University of Massachusetts

Medical School

67 Belmont Street \#201, Worcester,

Massachusetts, USA

E-mail: Isabel.emmerick@

umassmed.edu

Received: Nov 22, 2020

Approved: Apr 18, 2021

How to cite: Emmerick ICM, Singh A, Powers M, Lou F, Lin P, Maxfield $M$, et al. Factors associated with diagnosis of stages I and II lung cancer: a multivariate analysis. Rev

Saude Publica. 2021;55:112. https://doi.org/10.11606/s15188787.2021055003345

Copyright: This is an open-access article distributed under the terms of the Creative Commons Attribution License, which permits unrestricted use, distribution, and reproduction in any medium, provided that the original author and source are credited.

\section{ABSTRACT}

OBJECTIVE: To present the overall survival rate for lung cancer and identify the factors associated with early diagnosis of stage I and II lung cancer.

METHODS: This is a retrospective cohort study including individuals diagnosed with lung cancer, from January 2009 to December 2017, according to the cancer registry at UMass Memorial Medical Center. Five-year overall survival and its associated factors were identified by KaplanMeier curves and Cox's proportional hazards model. Factors associated with diagnosing clinical stage I and II lung cancer were identified by bivariate and multivariate backward stepwise logistic regression (Log-likelihood ratio (LR)) at 95\% confidence interval (CI).

RESULTS: The study was conducted with data on 2730 individuals aged 67.9 years on average, $51.5 \%$ of whom female, $92.3 \%$ white, and $6.6 \%$ never smoked. Five-year overall survival was $21 \%$. Individuals diagnosed with early-stage disease had a $43 \%$ five-year survival rate compared to $8 \%$ for those diagnosed at late stages. Stage at diagnosis was the main factor associated with overall survival [HR $=4.08$ (95\%CI: 3.62-4.59)]. Factors associated with early diagnosis included patients older than 68 years [OR $=1.23(95 \% \mathrm{CI}$ : 1.04-1.45)], of the female gender [OR $=1.47(95 \% \mathrm{CI}$ : $1.24-1.73)]$, white [OR = 1.63 (95\%CI: 1.16-2.30)], and never-smokers [OR = 1.37 (95\%CI: 1.01-1.86)]; as well as tumors affecting the upper lobe [OR $=1.46$ (95\%CI: $1.24-1.73)]$; adenocarcinoma [OR = 1.43 (95\%CI: 1.21-1.69)]; and diagnosis after 2014 [OR = 1.61 (95\%CI: 1.37-1.90)].

CONCLUSIONS: Stage at diagnosis was the most decisive predictor for survival. Non-white and male individuals were more likely to be diagnosed at a late stage. Thus, promoting lung cancer early diagnosis by improving access to health care is vital to enhance overall survival for individuals with lung cancer.

DESCRITORES: Lung Neoplasms, diagnosis. Early Detection of Cancer. Survival Analysis. Socioeconomic Factors. Healthcare Disparities. 


\section{INTRODUCTION}

Lung cancer is the leading cause of cancer death worldwide for both men and women. In 2020 , lung cancer accounted for the second most common cancer around the world, with 2.21 million cases and 1.80 million deaths $s^{1}$. From 2009-2013, deaths due to this cancer in the United States surpassed the records for breast, prostate, colorectal, and liver cancer combined. Moreover, authorities estimate that 131,880 deaths from this disease will occur in the country in $2021^{2}$.

Stage at diagnosis is the most decisive factor for lung cancer survival. The relative five-year survival rate for localized, stage I, non-small cell lung cancer (NSCLC) is approximately $57.4 \%$, compared to $5 \%$ for distant metastases. Surgical resection is the most effective treatment for NSCLC; however, approximately $40 \%$ of NSCLC patients are diagnosed at stage $4^{3}$.

Ethnic disparities exert significant influence on lung cancer diagnosis and treatment. Studies found higher mortality and incidence rates of the disease among African-Americans and non-Hispanics ${ }^{2,3}$. Moreover, Hispanics with stage I lung cancer had lower survival rates when compared with white individuals, besides presenting lower rates of lung resection and higher percentages of late-stage diagnosis ${ }^{4-6}$. Among other factors, such differences could be explained by the various cultural factors influencing the perception of minoritized groups regarding healthcare, including negative surgical beliefs and mistrust towards the healthcare system and providers ${ }^{4}$.

Individuals with low socioeconomic status and living in resource-deprived areas are at greater disadvantage when seeking timely treatment for lung cancer, which is partly attributed to the time taken to travel to these services. These patients often take longer to attain a proper and timely histological diagnosis and further treatment, which has a negative impact on their survival ${ }^{7,8}$.

For most cancers, early-stage diagnosis is associated with an increased overall survival ${ }^{9,10}$. Although several studies have investigated factors associated with the early-stage diagnosis of cancers affecting oral cavity ${ }^{10}$, breast ${ }^{9}$, and ovary ${ }^{11}$, research on factors associated with lung cancer early diagnosis are still scarce in the literature. Thus, understanding factors associated with early-stage diagnosis is important for identifying possible interventions in the health system and community levels to improve diagnosis and, consequently, survival. We hypothesize that delayed diagnosis and treatment for lung cancer is associated with a series of socioeconomic barriers, thus requiring initiatives to improve the access of minoritized populations and reducing disparities.

This study aims to estimate overall survival for lung cancer and to identify factors associated with diagnosis of clinical stages I and II of lung cancer, including race, socioeconomic status, health insurance status, and education level.

\section{METHODS}

This is a retrospective cohort study conducted with individuals aged 18 years and older who were registered as lung cancer patients at the institutional cancer registry (CR) from January 2009 to December 2017. The study was approved by the Institutional Review Board of the Medical School of University of Massachusetts, under IRB ID: H00008342.

Being part of the University of Massachusetts Cancer Program, accredited by the Commission on Cancer of the American College of Surgeons, the institutional CR was created in 1999. Every year, CR data is directly submitted to the National Cancer Database (NCDB), meeting all NCDB timeliness and data quality criteria. The registry also meets all federal and state requirements, so that incidence rates of all cancer cases diagnosed and/or treated in our medical center are reported to the Massachusetts State Cancer Registry 
- awarded the North American Association of Central Cancer Registries (NAACCR) Gold Standard for quality, completeness, and timeliness ${ }^{12}$. From this body, cases are reported to the Centers for Disease Control (CDC).

The CR staff collected all the required information on cancer patients through manual record review, following the North American Association of Central Cancer Registries (NAACCR) requirements. Cases are identified by an electronic medical record interface (EPIC interface) that considers information from the pathology department and departments using diagnostic codes from the disease index. This workflow guarantees that the CR is notified of all malignant cases, thus ensuring compliance with federal and state reporting laws. Established by Congress through the Cancer Registries Amendment Act in 1992 and administered by CDC, the National Program of Cancer Registries (NPCR) collects data on cancer occurrence, including type, extent, and location, as well as on the type of initial treatment and outcomes. In the last five years, loss to follow-up was $9.38 \%$, and the compliance targets for Standard 6.5 was $90 \%$. Every abstractor is subject to a quality review by a third-party company, and CR abstractors scores ranged from $96.78 \%$ to $99.52 \%$, which is higher than the required rate of $92 \%$.

Located in the city of Worcester, Central Massachusetts, the health system aims to promote culturally-sensitive excellence in clinical care, service, teaching, and research, thus improving the health of people from diverse communities of Central New England. Despite the high insurance coverage in the state of Massachusetts, disadvantaged patients such as those living in Worcester have more comorbidities and greater need for health education ${ }^{13}$.

This study primary outcome was diagnosis of clinical stage I and II $(1,1 \mathrm{~A}, 1 \mathrm{~B}, 2,2 \mathrm{~A}$, and 2B) lung cancer, whereby the percentage of individuals diagnosed at an early stage was calculated. Clinical staging is based on any information on the extent of the cancer obtained before initiation of thel definitive treatment ${ }^{14}$.

The secondary outcome was overall survival (OS), defined as the length of time from diagnosis (the date the patient was first diagnosed with lung cancer, usually by imaging considered highly suspicious for malignancy or date of biopsy) to death from all causes in months. These outcomes were defined according to the National Cancer Database ${ }^{14}$ and the US Census Bureau ${ }^{15}$.

Missing data accounted for less than $5 \%$, which will reflect on the total number of individuals (N), as shown in Tables 1 and 3.

Table 1 details other variables used in the study. For determining education and income level, the zip code of patient's residence reported at the time of diagnosis was used as a proxy. Data on zip codes were collected in the cancer registry and linked with the 2010 census data $^{15}$. The cut-off point was defined as the median values for the state of Massachusetts, so that zip codes referring to median-income geographic locations in the lower bracket characterized patients with income and education levels lower than the state median. Patient's distance from the healthcare center were calculated using an algorithm was developed using Google Maps.

Survival rates were analyzed considering the (I) adjusted survival analysis (Kaplan-Meier) for the overall cohort; the (II) adjusted survival analysis (Kaplan-Meier) according to stage at diagnosis; and (III) stratified cox proportional hazard models. Survival models were adjusted by age, gender, race, Hispanic origin, education level, income level, distance to healthcare services, smoking status, comorbidities, health insurance, histology, primary site of lesion, laterality, and year of diagnosis.

Factors associated with diagnosis of clinical stage I and II lung cancer (primary outcome) were identified by bivariate and multivariate backward stepwise logistic regression (Log-likelihood ratio statistic (LR)) at 95\%CI. Statistical analyses were performed using the Statistical Package for the Social Sciences (SPSS) version 22. 
Table 1. Characteristics of lung cancer patients at the UMass Memorial Health Care Center according to the cancer registry from 2009 to 2017.

\begin{tabular}{|c|c|c|c|}
\hline & & $n$ & $\%$ \\
\hline Total & & 2,730 & \\
\hline Age [Mean (SD)] & & 67.9 & 10.9 \\
\hline Age [Median (IQR)] & & 68.0 & $60-76$ \\
\hline Gender & Female & 1,407 & 51.5 \\
\hline \multirow[t]{3}{*}{ Race } & White & 2,521 & 92.3 \\
\hline & Black & 61 & 2.2 \\
\hline & Others & 84 & 3.1 \\
\hline Hispanic origin & Yes & 135 & 4.9 \\
\hline High education level & Yes & 1,022 & 37.4 \\
\hline High income level & Yes & 81 & 3.0 \\
\hline Distance to healthcare service (minutes) [Mean (SD)] & & 30 & 66 \\
\hline Distance to healthcare service (miles) [Mean (SD)] & & 23.9 & 75.8 \\
\hline \multirow[t]{3}{*}{ Smoking status } & Current smoker & 1,227 & 44.9 \\
\hline & Never used & 180 & 6.6 \\
\hline & Previous use & 1,281 & 46.9 \\
\hline \multirow[t]{4}{*}{ Number of comorbidities } & 0 & 603 & 22.1 \\
\hline & 1 to 3 & 860 & 31.5 \\
\hline & 4 to 6 & 413 & 15.1 \\
\hline & 7 to 10 & 854 & 31.3 \\
\hline \multirow[t]{4}{*}{ Health insurance } & Medicaid & 326 & 11.9 \\
\hline & Medicare & 1,631 & 59.7 \\
\hline & HMO_PPO & 632 & 23.2 \\
\hline & Non-specified & 121 & 4.4 \\
\hline \multirow[t]{3}{*}{ Histology } & adenocarcinoma & 1,255 & 46.0 \\
\hline & squamous cell carcinoma & 559 & 20.5 \\
\hline & Others & 851 & 31.2 \\
\hline \multirow[t]{3}{*}{ Primary site of lesion } & Lower Lobe & 762 & 27.9 \\
\hline & Middle Lobe & 115 & 4.2 \\
\hline & Upper Lobe & 1,459 & 53.4 \\
\hline \multirow[t]{2}{*}{ Laterality } & Right & 1,521 & 55.7 \\
\hline & Left & 1,088 & 39.9 \\
\hline \multirow[t]{8}{*}{ TNM clinical staging group categories } & Stage 1 & 44 & 1.6 \\
\hline & Stage $1 \mathrm{~A}$ & 551 & 20.2 \\
\hline & Stage 1B & 137 & 5.0 \\
\hline & Stage $2,2 \mathrm{~A}$ e $2 \mathrm{~B}$ & 170 & 6.2 \\
\hline & Stage 3 & 18 & 0.7 \\
\hline & Stage $3 \mathrm{~A}$ & 285 & 10.4 \\
\hline & Stage 3B & 220 & 8.1 \\
\hline & Stage 4 & 1,191 & 43.6 \\
\hline Year of diagnosis & 2014-2017 & 1,236 & 45.3 \\
\hline Early-stage diagnosis & Yes (Stage I and II) & 902 & 33.0 \\
\hline
\end{tabular}

\section{RESULTS}

The cancer registry recorded 2,730 lung cancer patients from January 2009 to December 2017. All patients were followed until August $31^{\text {st }}, 2018$, and five were lost to follow-up. Most patients were female (51.5\%) and white (94.6\%), with average age of 67.9 years and median age of 68.0 years (IQR 60-76); 6.6\% of them never smoked. Among the study cohort, $3 \%$ lived in areas with income level higher than the state median and $37 \%$ in areas with education level higher the state median (Table 1). 
In general, lung cancer patients presented a high number of comorbidities, with only $22.1 \%$ of them showing no comorbid conditions. Most patients (69\%) were diagnosed at a late stage, either clinical stages 3 or 4 (Table 1).

The five-year overall survival for the study cohort was $21 \%$, approaching $43 \%$ for patients diagnosed with early-stage lung cancer (Stage I and II) and dropping to $8 \%$ among individuals diagnosed at more advanced stages (Stage III and IV) (Figure). The median survival rate was a little over one year (12.7 months) for the overall cohort, reaching 49 months for diagnosed at an early stage and dropping to 9 months among those diagnosed at late stages.

Late-stage diagnosis was the most decisive factor for lung cancer overall survival [HR $=4.08$ (95\%CI:3.62-4.59)]. The final model included being older than 68 [(HR = 1.64;95\%CI: $1.49-1.80)]$ and male [(HR $=1.15(95 \% \mathrm{Cl}: 1.05-1.27)]$; having smoking habits [ $\mathrm{HR}=1.35(95 \% \mathrm{Cl}: 1.11-1.63)]$, more than three comorbidities [( $\mathrm{HR}=1.37(95 \% \mathrm{Cl}: 1.25-1.50)]$, histological diagnosis other than adenocarcinoma [ $\mathrm{HR}=1.27$ (95\% Cl: 1.15-1.39)], lower or middle lobe as primary site of lesion [HR $=1.10(95 \% \mathrm{Cl}: 1.00-1.21)]$; and being diagnosed before 2014 [HR $=1.24(95 \% \mathrm{Cl}: 1.12-1.37)]$ (Table 2). We found neither race nor ethnicity to be associated with overall survival. Similarly, survival was not associated with education level and mildly associated with living in a neighborhood with income level lower than the state median [HR = 1.30 (95\% Cl: 0.99-1.72)],

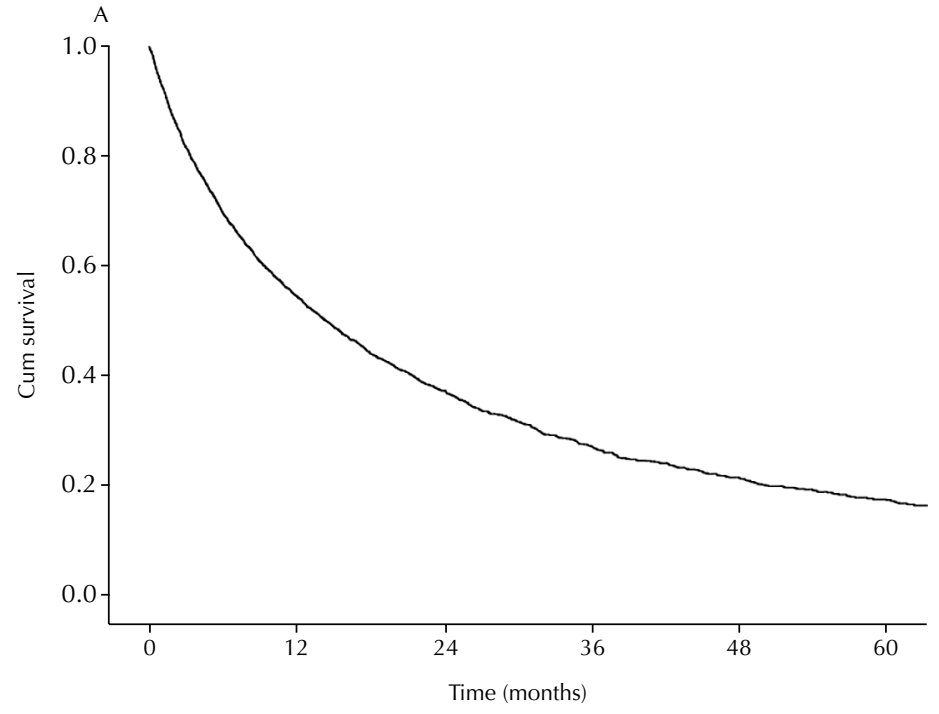

Interval start time

Number entering interval (overall) $\begin{array}{llllll}0 & 12 & 24 & 36 & 48 & 60\end{array}$ $2,725 \quad 742 \quad 742 \quad 450 \quad 292 \quad 195$

Number entering interval (early-stage diagnosis) $901 \quad 651 \quad 426 \quad 271 \quad 176 \quad 112$

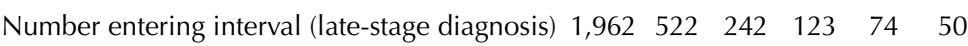

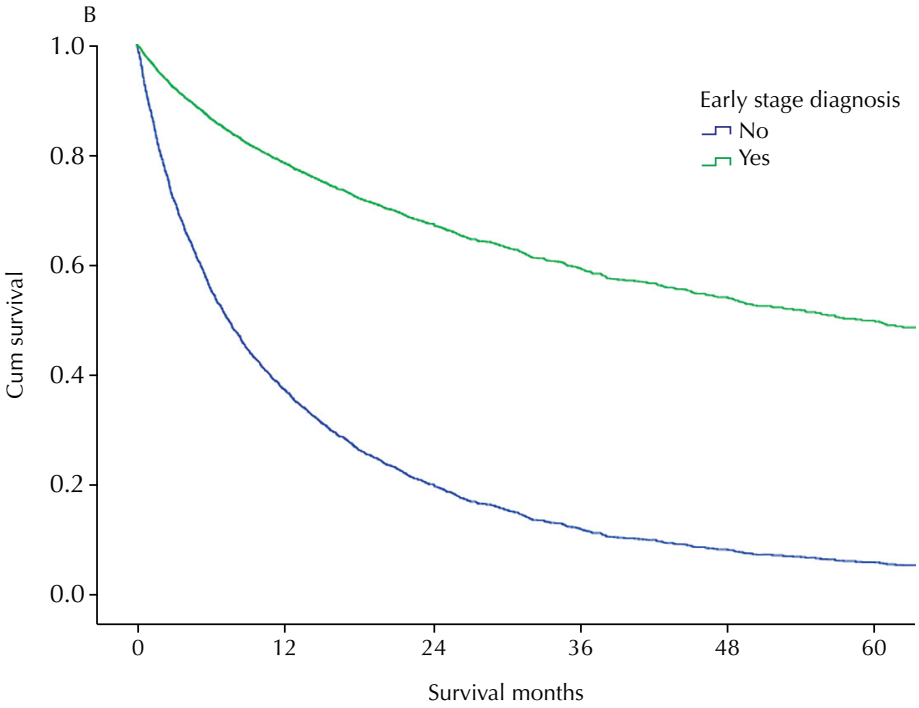

(A) Overall survival. (B) Adjusted Survival for early- versus late-stage diagnosis. Adjusted survival - cox regression model. Model was adjusted to Age, Gender, Race, Hispanic Origin, High Education Level, High Income level, Distance to Healthcare Service, Smoking status, Number of Comorbidities, Health Insurance, Histology, Primary Site of Lesion, Laterality, and Year of Diagnosis.

Figure. Five-year adjusted survival curves: (A) overall survival and (B) survival by stage at diagnosis

Table 2. Factors associated with overall survival in the cox proportional hazard final model, UMass Memorial Health Care cancer registry from 2009 to 2017.

\begin{tabular}{lcccc}
\hline & HR & \multicolumn{2}{c}{$\mathbf{9 5} \mathbf{C I}$} & $\mathrm{p}$ \\
\hline Diagnosed at late stage vs. early stage & 4.08 & 3.62 & 4.59 & 0.000 \\
Older than 68 & 1.64 & 1.49 & 1.80 & 0.000 \\
Male & 1.15 & 1.05 & 1.27 & 0.004 \\
Current or previous smoker & 1.35 & 1.11 & 1.63 & 0.002 \\
More than 3 comorbidities & 1.37 & 1.25 & 1.50 & 0.000 \\
Non-adenocarcinoma & 1.27 & 1.15 & 1.39 & 0.000 \\
Lower or middle lobe as primary site of lesion & 1.10 & 1.00 & 1.21 & 0.046 \\
Diagnosed before 2014 & 1.24 & 1.12 & 1.37 & 0.000 \\
\hline
\end{tabular}


$p$-value $=0.071$ in the bivariate analysis); however, such association was not maintained in the final cox regression model.

As stage at diagnosis was the most significant variable for a greater survival rate, we investigated factors associated with a higher likelihood of being diagnosed at stage I and II disease. Among the 2,598 cancer patients, 902 (35\%) were diagnosed with early-stage lung cancer (Table 3). This percentage increased over the years, going from 19.3\% in 2009 to $39.9 \%$ in 2017.

According to the bivariate analysis, early diagnosis was associated with: age greater than 68 years [OR $=1.25$ (95\%CI: $1.06-1.47)$ ]; female gender [OR = 1.46 (95\%CI: 1.32-1.83)]; white [OR $=1.58(95 \% \mathrm{CI}: 1.14-2.20)]$; never-smokers [OR $=1.40(95 \% \mathrm{CI}: 1.05-1.89)]$; upper lobe as primary site of lesion [OR = 1.47 (95\%CI: 1.25-1.73)]; adenocarcinoma [OR = 1.51 (95\%CI: 1.29-1.78)]; diagnosis after 2014 [OR = 1.67 (95\%CI: 1.42-1.96)]; and health insurance (Medicare or Medicaid) [OR $=1.22$ (95\%CI: 1.02-1.46)]. We found no association between early diagnosis and income or education level, nor with distance to healthcare services.

The most important factor associated with early diagnosis in the final multivariate analysis was being white [OR $=1.63$ (95\%CI: 1.16-2.30)], followed by year of diagnosis [OR $=1.61$ (95\%CI: 1.37-1.90)]. Age greater than 68 years [OR $=1.23(95 \% \mathrm{CI}: 1.04-1.45)]$,

Table 3. Characteristics of lung cancer patients at the UMass Memorial Health Care by stage, according to the cancer registry from 2009 to 2017.

\begin{tabular}{|c|c|c|c|c|c|c|c|}
\hline & & \multicolumn{2}{|c|}{ Stage I or II } & \multicolumn{2}{|c|}{$\underline{\text { Stage III and IV }}$} & \multicolumn{2}{|c|}{ Total } \\
\hline & & $\mathbf{n}$ & $\%$ & $\mathbf{n}$ & $\%$ & $\mathbf{n}$ & $\%$ \\
\hline Total & & 902 & 34.7 & 1,696 & 65.3 & 2,598 & 100.0 \\
\hline Age [Mean (SD)] & & 68.9 & 10.4 & 67.6 & 11.0 & 68.1 & 10.8 \\
\hline Age [Median (IQR)] & & 69.0 & $62-77$ & 68 & $60-76$ & 68 & $60-76$ \\
\hline Gender & Female & 525 & 58.2 & 801 & 47.2 & 1,326 & 51.0 \\
\hline \multirow[t]{2}{*}{ Race } & White & 851 & 94.3 & 1,549 & 91.3 & 2,400 & 92.4 \\
\hline & Black & 21 & 2.3 & 37 & 2.2 & 58 & 2.2 \\
\hline Hispanic origin & Yes & 34 & 3.8 & 94 & 5.5 & 128 & 4.9 \\
\hline High education level & Yes & 332 & 36.8 & 624 & 36.8 & 956 & 36.8 \\
\hline High income level & Yes & 32 & 3.5 & 42 & 2.5 & 74 & 2.8 \\
\hline \multicolumn{2}{|c|}{ Distance to healthcare service (minutes) [Mean(SD)] } & 30 & 60 & 36 & 1.2 & 0.6 & 1.2 \\
\hline \multicolumn{2}{|c|}{ Distance to healthcare service (miles)[Mean(SD)] } & 22.8 & 68.8 & 24.6 & 81.9 & 24 & 77.6 \\
\hline \multirow[t]{3}{*}{ Smoking status } & Current smoker & 356 & 39.5 & 818 & 48.2 & 1,174 & 45.2 \\
\hline & Never used & 75 & 8.3 & 94 & 5.5 & 169 & 6.5 \\
\hline & Previous use & 461 & 51.1 & 761 & 44.9 & 1,222 & 47.0 \\
\hline \multirow[t]{4}{*}{ Number of comorbidities } & No comorbidities & 147 & 16.3 & 428 & 25.2 & 575 & 22.1 \\
\hline & 1 to 3 comorbidities & 351 & 38.9 & 473 & 27.9 & 824 & 31.7 \\
\hline & 4 to 6 comorbidities & 137 & 15.2 & 249 & 14.7 & 386 & 14.9 \\
\hline & 7 to 10 comorbidities & 267 & 29.6 & 546 & 32.2 & 813 & 31.3 \\
\hline \multirow[t]{4}{*}{ Health insurance } & Medicaid & 92 & 10.2 & 222 & 13.1 & 314 & 12.1 \\
\hline & Medicare & 580 & 64.3 & 975 & 57.5 & 1555 & 59.9 \\
\hline & HMO_PPO & 197 & 21.8 & 402 & 23.7 & 599 & 23.1 \\
\hline & Non-specified & 30 & 3.3 & 83 & 4.9 & 113 & 4.3 \\
\hline \multirow[t]{3}{*}{ Histology } & adenocarcinoma & 478 & 53.0 & 724 & 42.7 & 1202 & 46.3 \\
\hline & squamous cell carcinoma & 230 & 25.5 & 301 & 17.7 & 531 & 20.4 \\
\hline & Others & 194 & 21.5 & 671 & 39.6 & 865 & 33.3 \\
\hline \multirow[t]{3}{*}{ Primary site of lesion } & Lower Lobe & 287 & 31.8 & 432 & 25.5 & 719 & 27.7 \\
\hline & Middle Lobe & 48 & 5.3 & 64 & 3.8 & 112 & 4.3 \\
\hline & Upper Lobe & 541 & 60.0 & 857 & 50.5 & 1398 & 53.8 \\
\hline \multirow[t]{2}{*}{ Laterality } & Right & 518 & 57.4 & 934 & 55.1 & 1452 & 55.9 \\
\hline & Left & 383 & 42.5 & 654 & 38.6 & 1037 & 39.9 \\
\hline Year of diagnosis & 2014-2017 & 487 & 54.0 & 701 & 41.3 & 1188 & 45.7 \\
\hline
\end{tabular}


Table 4. Factors associated with diagnosis of clinical stages I and II lung cancer in the final multivariate logistic regression, UMass Memorial Health Care cancer registry from 2009 to 2017.

\begin{tabular}{lcccc}
\hline & OR & & $\mathbf{9 5} \% \mathbf{C I}$ & $\mathrm{p}$ \\
\hline Age (older than 68 years old) & 1.23 & 1.04 & 1.45 & 0.01 \\
Female & 1.47 & 1.24 & 1.73 & 0.00 \\
White & 1.63 & 1.16 & 2.30 & 0.00 \\
Never-smoker & 1.37 & 1.01 & 1.86 & 0.04 \\
Upper lobe as primary site of lesion & 1.46 & 1.24 & 1.73 & 0.00 \\
Adenocarcinoma & 1.43 & 1.21 & 1.69 & 0.00 \\
Diagnosis after 2014 & 1.61 & 1.37 & 1.90 & 0.00 \\
\hline
\end{tabular}

female gender [OR = 1.47 (95\%CI: 1.24-1.73)], never-smokers [OR = 1.37 (95\%CI: 1.01-1.86)], upper lobe as primary site of lesion [OR $=1.46$ (95\%CI: 1.24-1.73)], and adenocarcinoma [OR $=1.43$ (95\%CI: 1.21-1.69)] were other relevant factors associated with the outcome (Table 4).

\section{DISCUSSION}

Our results indicate that stage at diagnosis was the primary factor associated with lung cancer survival. Even after adjusting for other variables, diagnosis at stages I and II was associated with a higher survival rate when compared to late-stage diagnosis (III and IV). Corroborating the literature on the theme $\mathrm{e}^{16,17}$, we found worse survival rates among older individuals. Moreover, male individuals showed poor overall survival when compared to females, also in line with other studies findings ${ }^{18,19}$. Individuals who never smoked presented increased survival at all stages diagnosis, which reiterates the fact that heavy smokers often have an unhealthy lifestyle, worsening their overall survival ${ }^{20}$.

We verified an association between increased survival of lung cancer patients and diagnosis after 2014, which is coherent with the advent of new therapies and techniques ${ }^{21}$. Stage at diagnosis and treatment are more important predictors of survival than race, suggesting that racial disparities in lung cancer survival may disappear provided that early detection efforts benefit both Black and white individuals in the same way ${ }^{22}$. This can be verified, for example, by the reduction in racial disparities in timely cancer treatment arising from the expansion of the Medicaid insurance health coverage ${ }^{23}$.

Over the last 10 years, lung cancer incidence rate has been decreasing at a $2.3 \%$ rate yearly, while that of death decreased at approximately $2.9 \%^{3}$. The percentage of early-stage diagnosis is increasing over time, which might indicate a progress on lung cancer awareness and a reflection of the compliance with screening recommendations. However, different populations still face great disparities in diagnosis and treatment ${ }^{23-25}$, suggesting a multifactorial problem. The ethnic and racial differences surrounding cancer care are complex, extending beyond access to healthcare - a broad term that includes not only the means to visit medical providers, but also the possibility of doing so timely. Thus, cancer care includes both individual components as well as health policies regulating care?

Identifying factors associated with early-stage diagnosis allow us to define intervention points within the health system that could improve access and quality of care, thus increasing overall survival.

In this study, we verified considerable race and gender disparities in early-stage lung cancer diagnosis. Several factors associated with early diagnosis - female gender, older age, and white race - have likewise been correlated with greater access to care and increased survival in other studies $^{26-29}$. Besides racial disparities reflected on the finding that Black patients are often diagnosed with lung cancer at later stages, these individuals also have lower stage-specific survival for most cancer types. When compared to white patients, the relative risk of death among Black individuals is $33 \%$ higher, even after adjusting for gender, age, and stage at diagnosis ${ }^{2}$. 
The gender differences in healthcare are multifactorial and influenced by structural, psychosocial, and behavioral determinants of health ${ }^{19,22,23}$. Studies show that women tend to seek more healthcare regarding mental and physical issues than men ${ }^{30}$, which might explain why female individuals accounted for a greater percentage of patients diagnosed with early-stage lung cancer in our study.

An important aspect of this study is that the cohort does not reflect the environment where the institution is located. Located in a diverse country, Worcester is likewise a relatively diverse city, whose population consists of $57.1 \%$ white individuals, $20.9 \%$ Hispanic or Latinos, $11.8 \%$ African-American, and 7.29\% Asians ${ }^{24}$. However, our study cohort consisted of $94.6 \%$ white individuals, $2.3 \%$ African-Americans, and 3.2\% other races. White individuals are almost twice as likely to be diagnosed with lunger cancer at an early stage. A recent study showed that Medicaid expansion as part of the Affordable Care Act (ACA) reduced racial disparities in access to care ${ }^{23}$. This finding indicates that strategies, policies, and programs must use the health system as an instrument to reduce structural disparities surrounding proper and timely access to healthcare.

This study did not intended to capture all predictors of access to diagnosis, for our cohort consists of individuals that have already accessed the healthcare system. Thus, further studies should adopt a community level approach to determine the barriers of access to healthcare.

This study has some limitations as to the census variables used to estimate income and education level, given that the zip code served as reference for analysis. For example, 'High-income' refers to areas whose median income was greater than the median income of the city of Massachusetts. However, individuals median income may be higher than that of the zip code in which they resides, so that their access to healthcare services may be different than the overall access of the population from that particular zip code area.

Despite being a single-center study, our study findings echo those from the literature, providing evidence of the important disparities in lung cancer diagnosis and treatment and highlighting the need for addressing to provide a more equitable access to health.

\section{CONCLUSIONS}

Stage at diagnosis was the most decisive factor for lung cancer survival. Non-white and male individuals were more likely of being diagnosed at late stages. This study providing information for the population attended at this institution, besides outlining the possible pathways to reduce inequities.

In a continuous effort to improve early diagnosis and equitable access to healthcare, further studies are needed to identify the barriers to access to lung cancer diagnosis and treatment at the community level, thus helping to reduce mortality and enhance overall survival.

\section{REFERENCES}

1. World Health Organization. Cancer. Geneva: WHO; 2021 [cited 2021 Apr 8]. Available from: https://www.who.int/news-room/fact-sheets/detail/cancer

2. Siegel RL, Miller KD, Fuchs HE, Jemal A. Cancer Statistics, 2021. CA Cancer J Clin. 2021;71(1):7-33. https://doi.org/10.3322/caac.21654

3. American Cancer Society, Cancer Statistics Center. Lung and bronchus statistics. Atlanta, GA; 2020 [cited 2020 Mar 25]. Available from: https://cancerstatisticscenter.cancer.org/\#!/cancer-site/Lung\%20and\%20bronchus

4. Lin JJ, Mhango G, Wall MM, Lurslurchachai L, Bond KT, Nelson JE, et al. Cultural factors associated with racial disparities in lung cancer care. Ann Am Thorac Soc. 2014;11(4):489-95. https://doi.org/10.1513/AnnalsATS.201402-055OC 
5. Weksler B, Kosinski AS, Burfeind WR, Silvestry SC, Sullivan J, D'Amico TA. Racial and ethnic differences in lung cancer surgical stage: an STS database study. Thorac Cardiovasc Surg. 2015;63(7):538-43. https://10.1055/s-0035-1546295

6. Wisnivesky JP, Halm EA, Bonomi M, Smith C, Mhango G, Bagiella E. Postoperative radiotherapy for elderly patients with stage III lung cancer. cancer. 2012;118(18):4478-85. https://doi.org/10.1002/cncr.26585

7. Andersen RM, Davidson PL, Baumeister SE. Improving access to care. In: Kominsky GF. Changing the U.S. health care system: key issues in health services policy and management. 4. ed. San Francisco, CA: Jossey-Bass; 2014. p.33-65.

8. Crawford SM, Sauerzapf V, Haynes R, Zhao H, Forman D, Jones AP. Social and geographical factors affecting access to treatment of lung cancer. Br J Cancer. 2009;101(6):897-901. https://doi.org/10.1038/sj.bjc.6605257

9. Iqbal J, Ginsburg O, Rochon PA, Sun P, Narod SA. Differences in breast cancer stage at diagnosis and cancer-specific survival by race and ethnicity in the United States. JAMA. 2015;313(2):165-73. https://doi.org/10.1001/jama.2014.17322

10. Watson JM, Logan HL, Tomar SL, Sandow P. Factors associated with early-stage diagnosis of oral and pharyngeal cancer. Community Dent Oral Epidemiol. 2009;37(4):333-41. https://doi.org/10.1111/j.1600-0528.2009.00470.x

11. Morris CR, Sands MT, Smith LH. Ovarian cancer: predictors of early-stage diagnosis. Cancer Causes Control. 2010;21(8):1203-11. https://doi.org/10.1007/s10552-010-9547-0

12. Manasanch EE, Smith JK, Bodnari A, McKinney J, Gray C, McDade TP, et al. Tumor registry versus physician medical record review: a direct comparison of patients with pancreatic neuroendocrine tumors. J Oncol Pract. 2011;7(2):111-6. https://doi.org/10.1200/JOP.2010.000097

13. Morère JF, Viguier J, Touboul C, Pivot X, Blay JY, Coscaas Y, et al. Lung cancer risks, beliefs and healthcare access among the underprivileged. Eur J Cancer Prev. 2015;24 Suppl:S82-6. https://doi.org/10.1097/CEJ.0000000000000143

14. American College of Surgeons, Comission on Cancer. FORDS -Facility Oncology Registry Data Standards: revised for 2015. Chicago, ILL; 2015 [cited 2020 Mar 25]. Available from: https://www.facs.org/-/media/files/quality-programs/cancer/coc/fords/fords-2015.ashx

15. United States Census Bureau. Decennial Census of Population and Housing. Washington, DC; 2010 [cited 2019 July 8]. Available from: https://www.census.gov/programs-surveys/decennial-census/data/datasets.html

16. Chen T, Zhou F, Jiang W,Mao R, Zheng H, Qin L, et al. Age at diagnosis is a heterogeneous factor for non-small cell lung cancer patients. J Thorac Dis. 2019;11(6):2251-66. https://doi.org/10.21037/jtd.2019.06.24

17. Tas F, Ciftci R, Kilic L, Karabulut S. Age is a prognostic factor affecting survival in lung cancer patients. Oncol Lett. 2013;6(5):1507-13. https://doi.org/10.3892/ol.2013.1566

18. Scaglia NC, Chatkin JM, Pinto JA, Tsukazan MTR, Wagner MB, Saldanha AF. Role of gender in the survival of surgical patients with nonsmall cell lung cancer. Ann Thorac Med. 2013;8(3):142-7. https://doi.org/10.4103/1817-1737.114297

19. Visbal AL, Williams BA, Nichols FC $3^{\text {rd }}$, Marks RS, Jett JR, Aubry MS, et al. Gender differences in non-small-cell lung cancer survival: an analysis of 4,618 patients diagnosed between 1997 and 2002. Ann Thorac Surg. 2004;78(1):209-215. https://doi.org/10.1016/j.athoracsur.2003.11.021

20. Lohse T, Rohrmann S, Bopp M, Faeh D. Heavy smoking is more strongly associated with general unhealthy lifestyle than obesity and underweight. PLoS One. 2016;11(2):e0148563. https://doi.org/10.1371/journal.pone.0148563

21. Jones GS, Baldwin DR. Recent advances in the management of lung cancer. Clin Med (Lond). 2018;18 Suppl 2:s41-6. https://doi.org/10.7861/clinmedicine.18-2-s41

22. Jones CC, Mercaldo SF, Blume JD, Blot WJ, Grogan EL, Aldrich MC, et al. racial disparities in lung cancer survival: the contribution of stage, treatment, and ancestry. J Thorac Oncol. 2018;13(10):1464-73. https://doi.org/10.1016/j.jtho.2018.05.032

23. Adamson BJS, Cohen AB, Estevez M,Magee K, Williams E, Gross CP, et al. Affordable Care Act (ACA) Medicaid expansion impact on racial disparities in time to cancer treatment. J Clin Oncol. 2019;37(18 suppl):LBA1-LBA1. https://doi.org/10.1200/JCO.2019.37.18_suppl.LBA1 
24. University of Washington, Institute for Health Metrics and Evaluation. US County Profile: Worcester County, Massachusetts. Seattle, WA: IHME; 2016 [cited 2020 April 15]. Available from: http://www.healthdata.org/sites/default/files/files/county_profiles/US/2015/County_Report_ Worcester_County_Massachusetts.pdf

25. Wolf A, Alpert N, Tran BV, Liu B, Flores R, Taioli E. Persistence of racial disparities in early-stage lung cancer treatment. J Thorac Cardiovasc Surg. 2019;157(4):1670-9.e4. https://doi.org/10.1016/j.jtcvs.2018.11.108

26. Bach PB, Cramer LD, Warren JL, Begg CB. Racial differences in the treatment of early-stage lung cancer. N Engl J Med. 1999;341(16):1198-205. https://doi.org/10.1056/NEJM199910143411606

27. Bach PB, Schrag D, Brawley OW, Galaznik A, Yakren S, Begg CB. Survival of blacks and whites after a cancer diagnosis. JAMA. 2002;287(16):2106-13. https://doi.org/10.1001/jama.287.16.2106

28. Forrest LF, Adams J, Wareham H, Rubin G, White M. Socioeconomic inequalities in lung cancer treatment: systematic review and meta-analysis. PLoS Med. 2013;10(2):e1001376. https://doi.org/10.1371/journal.pmed.1001376

29. Li CC, Matthews AK, Rywant MM, Hallgren E, Shah RC. Racial disparities in eligibility for low-dose computed tomography lung cancer screening among older adults with a history of smoking. Innov Aging. 2018;2 Suppl 1:750. https://doi.org/10.1093/geroni/igy023.2769

30. Thompson AE, Anisimowicz Y, Miedema B, Hogg W, Wodchis WP, Aubrey-Bassler K. The influence of gender and other patient characteristics on health care-seeking behaviour: a QUALICOPC study. BMC Fam Pract. 2016;17:38. https://doi.org/10.1186/s12875-016-0440-0

Funding: Division of Thoracic Surgery, Department of Surgery, University of Massachusetts Medical School, Worcester, Massachusetts, USA.

Authors' Contribution: Study design and planning: ICME, MP. Data collection, analysis and interpretation: ICME, AS, MP. Manuscript drafting or review: ICME, AS, MP, FL, MM, PL, KU. Approval of the final version: ICME, AS, MP, FL, MM, PL, KU. Public responsibility for the content of the article: ICME.

Conflict of Interests: The authors declare no conflict of interest. 